\title{
T Cell Clones from Schistosoma haematobium Infected and Exposed Individuals Lacking Distinct Cytokine Profiles for Th1/Th2 Polarisation
}

\author{
T Mduluza/ ${ }^{+}$, PD Ndhlovu/*, N Midzi, C Mary***, CP Paris***, CMR Turner**, \\ SK Chandiwana, MEJ Woolhouse****, AJ Dessein***, P Hagan**
}

\begin{abstract}
Biochemistry Department, University of Zimbabwe, Box MP 167, Mount Pleasant, Harare, Zimbabwe *Blair Research Laboratory, Harare, Zimbabwe **IBLS Division of Infection and Immunity, University of Glasgow, Glasgow, UK ***INSERM U399 Faculte de Medicine, Marseille, France ****Department of Zoology, University of Oxford, Oxford, UK
\end{abstract}

$T$ cell clones were derived from peripheral blood mononuclear cells of Schistosoma haematobium infected and uninfected individuals living in an endemic area. The clones were stimulated with $\mathrm{S}$. haematobium worm and egg antigens and purified protein derivative. Attempts were made to classify the $T$ cell clones according to production of the cytokines $I L-4, I L-5$ and IFN- $\gamma$. All the $T$ cell clones derived were observed to produce cytokines used as markers for the classification of Th1/Th2 subsets. However, the 'signature' cytokines marking each subset were produced at different levels. The classification depended on the dominating cytokine type, which was having either Th0/1 or Th0/2 subsets. The results indicated that no distinct cytokine profiles for polarisation of Th1/Th2 subsets were detected in these S. haematobium infected humans. The balance in the profiles of cytokines marking each subset were related to infection and re-infection status after treatment with praziquantel. In the present study, as judged by the changes in infection status with time, the T cell responses appeared to be less stable and more dynamic, suggesting that small quantitative changes in the balance of the cytokines response could result in either susceptibility or resistant to $\mathrm{S}$. haematobium infection.

Key words: Schistosoma haematobium - cytokines - T cell clones - immunoregulation - T helper subsets

Evidence accumulated has underlined the existence of functionally distinct $\mathrm{T}$ helper $(\mathrm{Th})$ cell subsets. These $\mathrm{Th}$ cells originate from $\mathrm{CD}^{+} \mathrm{T}$ cell precursors and are defined by the cytokines they produce (Mosmann et al. 1986, Mosmann \& Coffman 1989). These subsets have been shown to have a central role in the control and regulation of many immune responses including those directed against parasitic infections such as Leishmania major and Schistosoma mansoni. In murine models of $S$. mansoni infection, a well defined Th subset dichotomy has been reported in which T helper1 (Th1) produce interferon gamma (IFN- $\gamma$ ) and tumour necrosis factor- $\beta$ (TNF- $\beta$ ), which activate macrophages as part of a delayed type hypersensitivity (DTH) reaction. The reaction was reported to provide protection against $S$. mansoni infection in mice (Sher et al. 1990).

\footnotetext{
The study was financed by a grant from the European Commission contract number TS3.CT.930248.

${ }^{+}$Corresponding author. Fax: 263-4-333678/333407. E-mail: mduluza@blair.co.zw/mduluza@hotmail.com Received 14 May 2001

Accepted 25 July 2001
}

Th2 lymphocytes are known to produce IL-4, IL-5, IL-10 and IL-13, which are essential for the production by B cells of IgE, IgG1, IgA and IgM antibody isotypes and eosinophil and mast cell activation. Th2 type cells are believed to be essential in human protection from schistosome infections but have been shown to play a role in pathology which accompanies the deposition of eggs in the tissues of $S$. mansoni infected mice (Sher \& Coffman 1992).

The patterns of cytokines produced by mouse $\mathrm{T}$ cell clones seems adequately defined by the Th1 and Th2 labels (Mosmann \& Coffman 1989). Initially the same classification was applied to human $\mathrm{T}$ cell clones but the results of studies of $\mathrm{T}$ cell clones derived from patients with schistosomiasis showed a lack of distinct Th1/Th2 polarisation observed in murine models. Instead, responses ranged from Th0, Th1, Th2 to Th3 (Romagnani 1991, Couissinier-Paris \& Dessein 1995). Many groups have reported peripheral mononuclear cells (PBMC) cultures from schistosomiasis infected individuals producing IL-2, IL-4, IL-5, IL-6, IL-10 and IFN- $\gamma$ (Roberts et al. 1993, Viana et al. 1994, Williams et al. 1994, Araujo et al. 1996, Grogan et al. 1996). This lack of confirmation of the Th1/Th2 concept in hu- 
man schistosomiasis suggests that the observed differences in the cytokine production in the mouse are more likely to reflect differences between the murine models and humans (Couissinier-Paris \& Dessein 1995). Additional studies are therefore required on human schistosomiasis from different transmission areas in endemic zones and on different schistosome species.

The studies cited above have associated the dominance of the particular sets of cytokines produced by PBMC to a particular Th cell subset and are therefore of limited value in determining the precise details of the Th cell dichotomy of the immune response to schistosome infection. In contrast to studies using PBMC, the use of $\mathrm{T}$ cell clones provides an opportunity to examine responses under well-defined culture conditions. The present study was designed to develop $\mathrm{T}$ cell clones from the PBMC from $S$. haematobium infected and uninfected children living in an area of high transmission of S. haematobium. Studies of the cytokine production of such $\mathrm{T}$ cell clones would shed some light on the immune processes triggered by natural repeated exposures to $S$. haematobium infection.

\section{MATERIALS AND METHODS}

Study area and population - The study population was selected from a farming community of The Burma Valley Area, Eastern Highlands of Manicaland Province in Zimbabwe. The farming activities were based on both irrigation and on seasonal rains. There is a permanent river which flow into a dam and several seasonal river tributaries. The community has low S.mansoni prevalence (about 4\%, Ndhlovu, pers. commun.) and a high $S$. haematobium infection prevalence and subjects were selected from Valhalla primary school which is situated in this community.

Four school children, aged 10, 11, 11 and 12 years were selected for a detailed study of their cellular immune response by cloning $\mathrm{T}$ cells derived from their PBMC prior to treatment with praziquantel. Two of the children were infected, one moderately and the other heavily with $S$. haematobium as determined by egg counts on urine specimens. Neither of these children had received treatment in the two years before the study. The other two children were uninfected.

Parasitology - Urine samples for parasitological examination for $S$. haematobium infection were collected from all the individuals on three consecutive days and were processed on the day of collection. Samples were collected between 10 a.m. and 2 p.m. to coincide with peak S. haematobium egg excretion in urine (Warren et al. 1978). Urine samples were examined for urinary schistosomiasis by filtration of $10 \mathrm{ml}$ samples after thorough mixing us- ing $13 \mathrm{~mm}$ polyamide $\mathrm{Nytrel}^{\mathrm{TM}}$ filters and 5-10\% Lugol's iodine stain, to help visualise the eggs (Mott et al. 1982). The filters were examined for eggs of $S$. haematobium, and counts were expressed as eggs per $10 \mathrm{ml}$ of urine (ep10 ml). Intensity of infection was classified as negative: no eggs detected; very light: $<10$ ep $10 \mathrm{ml}$; light: 10 to $<50$ ep $10 \mathrm{ml}$; or heavy: 50 or more ep $10 \mathrm{ml}$.

Stool samples were examined by the Kato-Katz technique as modified by Peters et al. (1980). Stool samples were collected and processed to exclude those with $S$. mansoni infection from the study.

Collection of venous blood - About $20 \mathrm{ml}$ of venous blood were collected from the cubital vein of each child by venepuncture using $21 \mathrm{G}$ cannulae into sterile syringes pre-loaded with $5-10 \mathrm{U} / \mathrm{ml}$ heparin for later separation and collection of PBMC. Samples were transported in a cooler box and were processed at the laboratory within $2 \mathrm{~h}$ of collection.

Treatment - All children were treated with praziquantel, given as a single dose of $40 \mathrm{mg} / \mathrm{kg}$ body weight, at the end of the first (pre-treatment) examination and retreated at the end of the 2 year follow-up.

PBMC separation - Blood was layered gently into sterile LeucoSep tubes, prespun with Lymphoprep $^{\mathrm{TM}}$ (Nycomed) and centrifuged at 450 $\mathrm{xg} / 20 \mathrm{~min}$. The method for cell separation employed density gradient centrifugation of anti-coagulated blood on a dense solution of lymphoprep (Nycomed), using a modified method (Boyum 1968, Hunt 1978). The white buffy layer containing the PBMC at the plasma/lymphoprep interface was pipetted into another sterile tube. The remaining lymphoprep with the red cells and granulocytes was discarded. Aspirated PBMC were resuspended in complete media (RPMI1640 supplemented with $2.4 \mathrm{mM}$ sodium hydrogen carbonate, $1 \%$ gentamycin, 2 mM L-glutamine, 10\% FCS serum, $1 \%$ non essential amino acids, $1 \%$ sodium pyruvate and $25 \mathrm{mM} \beta$-2-Mercarptoethanol) and washed by centrifugation at $350 \mathrm{xg} / 15 \mathrm{~min}$. The cells were washed again in complete medium and collected by pelleting at $300 \mathrm{xg} / 10 \mathrm{~min}$. The supernatant was discarded and the cells resuspended into $3 \mathrm{ml}$ of complete media. The resuspended cells were aliquoted and distributed equally into three $1.8 \mathrm{ml}$ sterile Nunc tubes, mixed with $1 \mathrm{ml}$ freezing medium (RPMI1640, 25\% FCS, 20\% DMSO) and immediately transferred for freezing by gradient freezing in liquid nitrogen following a given standard curve (Hviid 1990).

PBMC proliferation assays using tritiated thymidine - The cryopreserved PBMC were rapidly thawed at $37^{\circ} \mathrm{C}$ and transferred asceptically into 10 $\mathrm{ml}$ washing media (RPMI1640, 1\% gentamycin, 5\% 
human $\mathrm{AB}$ serum). The cells were washed by centrifugation at $300 \mathrm{xg} / 10 \mathrm{~min}$ to remove the DMSO and resuspended in $1 \mathrm{ml}$ complete medium containing $10 \% \mathrm{AB}$ serum and $50 \mu \mathrm{g} / \mathrm{ml}$ gentamycin. Cell viability and concentration was determined by counting $20 \mu \mathrm{l}$ of the resuspended cells in trypan blue $(0.2 \% \mathrm{w} / \mathrm{v})$. A final viable cell concentration of approximately $1 \times 10^{6}$ cells $/ \mathrm{ml}$ was cultured in $200 \mu \mathrm{l}$ volumes in duplicate in 96 well flat bottomed culture plates. The cells from each individual had a negative control (unstimulated cells) and as positive control, cells stimulated with $10 \mu \mathrm{g} / \mathrm{ml}$ Phytohaemaglutinin (PHA). The S. haematobium antigens SEA and SWAP were used to study specific stimulation of the cells at $10 \mu \mathrm{g} / \mathrm{ml}$. The plates were incubated in a $5 \% \mathrm{CO}_{2}$ humidified incubator at $37^{\circ} \mathrm{C}$ for 6 days. The cells were pulsed with $1 \mu \mathrm{Ci}$ tritiated thymidine (methyl ${ }^{3} \mathrm{H}$-thymidine, Amersham, UK) after 5 days incubation, and further incubated for approximately $18 \mathrm{~h}$. The cells were then harvested onto filters using a semi-automated cell harvester and the filters rinsed with distilled water to remove unincorporated tritiated thymidine.

The amount of tritiated thymidine incorporation induced by antigen or mitogen was determined with a Liquid Scintillation Analyser (TRICAB ${ }^{\mathrm{TM}}$, Model 1600 CA Packard USA). Data were expressed as stimulation index of mean counts per minute (SI) calculated as follows: SI of mean cpm = mean counts from stimulated cells divided by mean counts from control (unstimulated) cells.

$T$ cell lines for $T$ cell clone derivation and $T$ cell clones - Short term T cell lines (TCL) were established from the PBMC of subjects numbers 309, 311,329 and 350, all from the high transmission area. The frozen PBMC were retrieved from liquid nitrogen and rapidly thawed with constant agitation, until a small ice crystal remained, they were then transferred to incomplete media (RPMI1640, $1 \%$ gentamycin and $50 \mu \mathrm{g} / \mathrm{ml}$ gentamycin. After washing twice, the cells were resuspended in complete media containing $10 \%$ human $\mathrm{AB}$ serum and seeded at $1 \times 10^{6}$ cells $/ \mathrm{ml}$ in the presence of $20 \mu \mathrm{g} /$ $\mathrm{ml} \mathrm{SEA,} \mathrm{SWAP} \mathrm{or} \mathrm{PPD.} \mathrm{After} 6$ days at $37^{\circ} \mathrm{C}$ in $5 \%$ $\mathrm{CO}_{2}$ in humidified air, cells were washed and resuspended in complete media containing $10 \%$ human AB serum supplemented with $10 \mathrm{IU} / \mathrm{ml}$ human IL-2, and cultured for 5-10 days. After the first stimulation the TCL were directly cloned by the limiting dilution method (Lefkovits \& Waldmann 1984). Cells were seeded at 0.3 or 1 cell/well in the presence of irradiated (3500 rads) heterologous PBMC as feeder cells ( $5-7.5 \times 10^{5}$ cells $\left./ \mathrm{ml}\right)$, PHA-P at $2 \mu \mathrm{g} / \mathrm{ml}$ and $\mathrm{hIL}-2(20 \mathrm{IU} / \mathrm{ml})$. The clones were left to proliferate and expand for 2-4 weeks, with repeated observation. Plates with less than $30 \%$ of the wells with growing clones were selected for further study and the clones were then expanded first in 96 well round bottomed plates then 48 well plates and finally in 24 well plates $(1 \mathrm{ml} /$ well $)$ by re-stimulation every 15 days with irradiated feeder cells at $7.5 \times 10^{5}$ cells/ $\mathrm{ml}$, with $2 \mu \mathrm{g} / \mathrm{ml}$ PHA-P and $20 \mathrm{IU} / \mathrm{ml}$ hIL-2. T cell clones (TCC) were maintained in complete media with $10 \%$ FCS supplemented with $20 \mathrm{IU} / \mathrm{ml} \mathrm{hIL-2}$ between each stimulation.

Antigen specificity test of clones - TCC were tested for their proliferative response to parasite antigen 10-15 days after the last stimulation. After two washes in RPMI supplemented with $50 \mu \mathrm{g} / \mathrm{ml}$ gentamycin, the cells were suspended in complete media with $10 \%$ FCS and seeded at $2 \times 10^{4}$ cells per well in flat bottomed microtitre plates containing 5 x $10^{4}(\mathrm{cells} / \mathrm{ml})$ irradiated (3500 rad) autologous PBMC. After addition of parasite antigen or (nonspecific) mitogen (PHA-P), cultures were incubated for 3 days at $37^{\circ} \mathrm{C}$ in $5 \% \mathrm{CO}_{2}$ in an humidified air. Cultures were pulsed with 5-bromo-2'-deoxyuridine (BrdU; Boehringer Mannheim) during the last 16$18 \mathrm{~h}$. After aspirating the labelling media, cells were briefly further cultured in incomplete media for $2 \mathrm{~h}$ at $37^{\circ} \mathrm{C}$ in $5 \% \mathrm{CO}_{2}$ humidified incubator. The cells were then washed and the plates dried before fixing and denaturation of the cells with Lysis and Fixing reagent (FixDenat ${ }^{\mathrm{TM}}$ ) solution and incubating for $30 \mathrm{~min}$ at room temperature. The FixDenat was removed by washing $3 x$, the anti-BrdU labelled with peroxidase dismutase (POD) added and incubated for $3 \mathrm{~h}$ at room temperature. The plates were then washed $3 \mathrm{x}$ before adding substrate and the absorbance measured using an ELISA reader set at $405 \mathrm{~nm}$ with $630 \mathrm{~nm}$ as the reference wavelength.

Stimulation of TCC for cytokine production TCC were stimulated for assay of lymphokine secretion 10-15 days after the stimulation with feeder cells and PHA-P. The feeder cells have a limited life-span and having been irradiated were considered to be no longer active, and the TCC produced no lymphokine spontaneously. The TCC were washed twice and seeded at $10^{5}$ cells/ $100 \mu \mathrm{l}$ in flat bottomed microtitre plates in complete media with $10 \% \mathrm{FCS}$. The cells were then incubated for $24 \mathrm{~h}$ at $37^{\circ} \mathrm{C}$, in media alone or in the presence of mitogenic stimuli: $20 \mathrm{ng} / \mathrm{ml}$ anti-CD3 antibody plus $10 \mathrm{ng} / \mathrm{ml}$ PMA (Phorbol-12-Myristate 13-Acetate) and $2 \mathrm{ng} /$ $\mathrm{ml}$ PHA-P plus $10 \mathrm{ng} / \mathrm{ml}$ PMA. Cell free supernatants were collected $24 \mathrm{~h}$ later under sterile conditions and were stored at $-70^{\circ} \mathrm{C}$ before assaying for cytokines. All the supernatants derived from TCC were tested for IL-4, IL-5 and INF- $\gamma$.

Cytokine titration by ELISA - Cytokine detection was performed on the supernatants harvested after $24 \mathrm{~h}$ mitogenic stimulation. The NuncImmunoplates Maxisorp ${ }^{\mathrm{TM}}$ (InterMed) were coated 
with anti-human monoclonal antibodies $(\mathrm{mAb})$ at $0.5 \mu \mathrm{g} / \mathrm{ml}$ for IFN- $\gamma$ and at $1 \mu \mathrm{g} / \mathrm{ml}$ for IL- 4 and IL-5 in carbonate/bicarbonate buffer at $\mathrm{pH} 9.6$ at $4^{\circ} \mathrm{C}$ on a shaker. After the overnight incubation, the plates were washed twice with PBS containing $0.05 \%$ Tween 20 at pH 7.2 and then blocked with complete RPMI for $1 \mathrm{~h}$ at room temperature. The RPMI was aspirated and the plates washed once with PBS containing $0.05 \%$ Tween 20 . Standards for each cytokine were added in duplicate for each concentration within the range $15-2000 \mathrm{pg} / \mathrm{ml}$. Then various dilutions of clonal supernatants were added in duplicate and diluted in complete RPMI at $1 / 4$ for the control, 1/5, 1/25 and 1/125 for the samples and incubated over night at $4^{\circ} \mathrm{C}$ on a shaker. After three washes with PBS+0.05\% Tween 20, the plates were incubated for $4 \mathrm{~h}$ at room temperature with a second anti-human biotinylated monoclonal antibody specific for each cytokine, at $0.5 \mu \mathrm{g} / \mathrm{ml}$ for IFN- $\gamma, 1$ $\mu \mathrm{g} / \mathrm{ml}$ for IL-4 and IL-5. After washing $3 \mathrm{x}$ with PBS+0.05\% Tween 20, streptavidin-alkaline phosphatase conjugate or an alkaline phosphatase-conjugated $\mathrm{mAb}$ at a dilution of $1 / 1000$ for IFN- $\gamma$ and IL-4, and at a dilution of 1/2500 for IL-5 then incubated for $2 \mathrm{~h}$ at room temperature. Enzymatic activity was determined by incubating the plates with $\mathrm{p}$ nitrophenyl phosphate (SIGMA FAST) ${ }^{\mathrm{TM}}$. Absorbance was read at $405 \mathrm{~nm}$ with $630 \mathrm{~nm}$ as the reference wavelength on a DIAS Multiscan reader (Dynatech Laboratories). The standard curves were calculated for each plate according to the sigmoid curve equation: $\mathrm{Y}=\mathrm{D}+(\mathrm{A}-\mathrm{D}) /\left(1+(\mathrm{X} / \mathrm{C})^{\mathrm{B}}\right)$ Where $\mathrm{X}$ is the cytokine concentration and $\mathrm{Y}$ is the absorbance at $405 \mathrm{~nm}$; A, B, C and D are constants.

$\mathrm{CD}^{+}$and $\mathrm{CD}^{+}$surface phenotyping - Approximately $10^{5}$ cells/well of each TCC were placed into each of three wells for assessment of CD4 and CD8 numbers, with the third well serving as the control. The TCC were then centrifuged and the culture medium supernatant aspirated. The cells were washed with $200 \mu \mathrm{l}$ PBS buffer by centrifugation at $400 \mathrm{xg} / 5 \mathrm{~min}$. The supernatant was discarded and the cells resuspended in a solution containing mouse anti-human IgG primary monoclonal antibodies (diluted in PBS with $0.1 \%$ BSA) specific for CD4 and CD8 surface markers. The TCC were then incubated at room temperature for 45-60 min, after which the cells were washed twice in $150 \mu \mathrm{l}$ of PBS by centrifugation at $400 \mathrm{xg} / 5 \mathrm{~min}$. Then $50 \mu \mathrm{l}$ of FITC-conjugated anti-mouse IgG diluted 50x in PBS with $0.1 \%$ BSA was added and incubated at room temperature for 45-60 min. The cells were washed twice and then re-suspended in PBS + 0.1\% BSA + EDTA. Cells were mounted in PBS $+50 \%$ glycerol (1:1 cell suspension: PBS/glycerol) and observed by fluorescent microscopy.
Statistical analysis - The levels of IFN- $\gamma$, IL-4 and IL-5 were expressed as $\mathrm{pg} / \mathrm{ml}$. The data sets were mostly not normally distributed hence nonparametric tests were used for the analyses. Wilcoxon matched pairs sign ranks test was used for comparison between two cytokine phenotypes of each clone. Kruskal-Wallis one-way ANOVA was used to compare the cytokine levels of all the clones. The Mann-Whitney Rank sum test was used to compare the responses of the antigen specific and non-specific clones.

To reduce the risk of type 1 errors arising from making multiple pairwise comparisons, Bonferroni's method was applied which uses the function $p=\alpha /$ $\mathrm{m}$, where $\alpha$ is $\mathrm{p}$ constant for statistical comparison and $\mathrm{m}$ is the number of comparisons. When comparisons were made of levels of cytokines produced by TCC from an individual, the revised significance level was; $p=0.05 / 3=0.017$; because three comparisons (PPD, SWAP and SEA) were made at each time point.

Each clone was categorised as a $\mathrm{T}$ helper class using a ratio obtained from the measured classes of cytokine IFN- $\gamma$, IL- 4 and IL- 5 . The ratio was obtained using the following expression:

$$
\mathrm{x}=\mathrm{IL}-4: \mathrm{IFN}-\gamma \text { or IL-5:IFN- } \gamma
$$

Based on the ratio, the phenotype of each clone was reported as Th1, Th0/1, Th0/2 or Th2 as shown below:

$$
\begin{array}{ll}
\mathrm{x} \leq 0.1 & \text { then the clone is Th1 } \\
0.1<\mathrm{x} \leq 1 & \text { then the clone is Th0/1 } \\
1<\mathrm{x} \leq 10 & \text { then the clone is Th0/2 } \\
\mathrm{x}>10 & \text { then the clone is Th2 }
\end{array}
$$

A similar classification has been proposed for classification of human TCC during leishmaniasis and schistosomiasis mansoni although it remains to be tested in further studies (Couissinier-Paris, pers. comm.).

\section{RESULTS}

Parasitology - Of the four children selected from the high transmission area, two were infected with $S$. haematobium and the other two were not infected as indicated by the urine examinations. Parasitology results for the four children at various times during the study are shown in Table I. Child number 309 , was heavily infected with a mean egg counts of 53 eggs per $10 \mathrm{ml}$ of urine. The other child, number 350 , was moderately infected with an egg output of 20 eggs per $10 \mathrm{ml}$ of urine. The heavily infected child became heavily reinfected by one year post treatment (115 ep10ml) and was re-treated, while the other initially moderately infected child, 350 , remained uninfected during the two year follow-up. The two children initially uninfected were 
TABLE I

Results of Schistosoma haematobium parasitological examination (eggs $/ 10 \mathrm{ml}$ of urine) over a two year follow-up period of the children whose peripheral blood mononuclear cells were cloned. The egg counts were determined by filtration of $10 \mathrm{ml}$ of urine collected on three consecutive days

\begin{tabular}{lcccccrrr}
\hline Subject & Baseline & \multicolumn{7}{c}{ Months post-treatment } \\
\cline { 3 - 9 } (age) & pre-treatment & 3 & 6 & 9 & 12 & 15 & 18 & 24 \\
\hline Infected & & 0 & 0 & 0 & 0 & 0 & 115 & 70 \\
$309(11)$ & 20 & 0 & 0 & 0 & 0 & 0 & 0 & 0 \\
$350(12)$ & & & & & & & & \\
Uninfected & 0 & 0 & 0 & 55 & 82 & 27 & 11 & ND \\
$329(10)$ & 0 & 0 & 0 & 0 & 0 & 7 & 7 & 4 \\
$311(11)$ & & & & & & & &
\end{tabular}

ND: not done

found to be infected when examined at six months post-treatment (child 329) or one year post treatment (child 311). The intensities of infection in these children were heavy and light, respectively (Table I).

Proliferation - The PBMC from each of the children were examined for proliferative responses to mitogen and worm and egg antigens. The proliferative responses of PBMC from children 329 (uninfected), 309 (infected) and 350 (infected) were not statistically significantly different from one another but there was a clear biological trend of the PBMC from child 329 (uninfected) having higher levels of proliferation to schistosome antigen. The proliferative responses of PBMC from child 311 (uninfected) were higher than the responses of the PBMC from the other three children (Fig. 1).

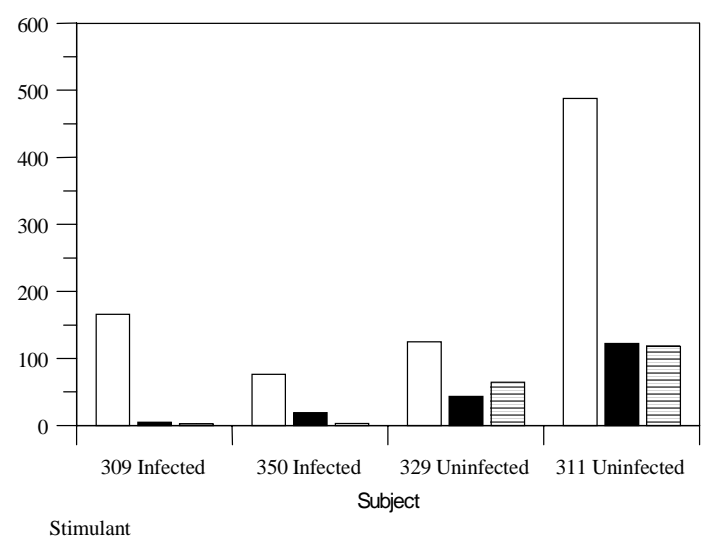

Stimulant

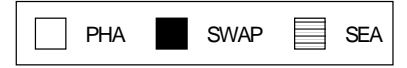

Fig. 1: the levels of proliferation to PHA and schistosome antigen (SWAP and SEA) stimulation of peripheral blood mononuclear cells from children before deriving $\mathrm{T}$ cell lines for $\mathrm{T}$ cell cloning. Proliferation levels were determined by tritiated thymidine incorporation.
TCC - antigen specificity and surface phenotype - After expanding the TCC, each clone was tested for antigen specificity using the antigen used in their derivation. The PBMC from the heavily infected child had few TCC testing positive to the worm and egg antigens the general response could be related to the antigen stimulation assays in which the response was low. The other children had high numbers of TCC testing positive to the worm and egg antigens used to derive them. The total number of TCC derived which were antigen specific were used in the analysis of the cytokines profiles and ratios. All the tested TCC were $\mathrm{CD}^{+}$(positive).

Cytokine profiles, ratios and $\mathrm{T}$ helper subsets

Child 309 (heavily infected) - The TCC from the heavily infected child gave a high IL-5:IFN- $\gamma$ ratio for the clones derived from worm and egg antigen stimulation, while the egg antigen derived TCC showed a high IL-4:IFN- $\gamma$ ratio. The PPD derived TCC showed a low ratio for both comparison of IL4:IFN- $\gamma$ and IL-5:IFN- $\gamma$ (Fig. 2). The infected child, 309 , showed an IL-5:IFN- $\gamma$ ratio of approximately 10 , indicating the levels of IL- 5 being 10 times the levels of IFN- $\gamma$, indicating the cytokine balance of the response tipping towards a Th2 type.

TCC derived from either worm or egg antigen stimulation of PBMC from the heavily infected child, 309 , using IL-4:IFN- $\gamma$ ratio, proved to be predominantly classified as Th0/2 subset and a small number of TCC being classified as Th0/1, Th1 and Th2 type. Using the IL-5:IFN- $\gamma$ ratio, some of the T cell clones were classified as Th2 type. However, the PPD derived TCC produced cytokines that led to their being classified as Th0/2 (Table IIa).

Child 350 (moderately infected) - The moderately infected child, 350, had TCC derived from worm antigen stimulation of PBMC giving a high IL-5:IFN$\gamma$ ratio, while the egg antigen derived TCC showed a high IL-4:IFN- $\gamma$ ratio. The PPD derived TCC 


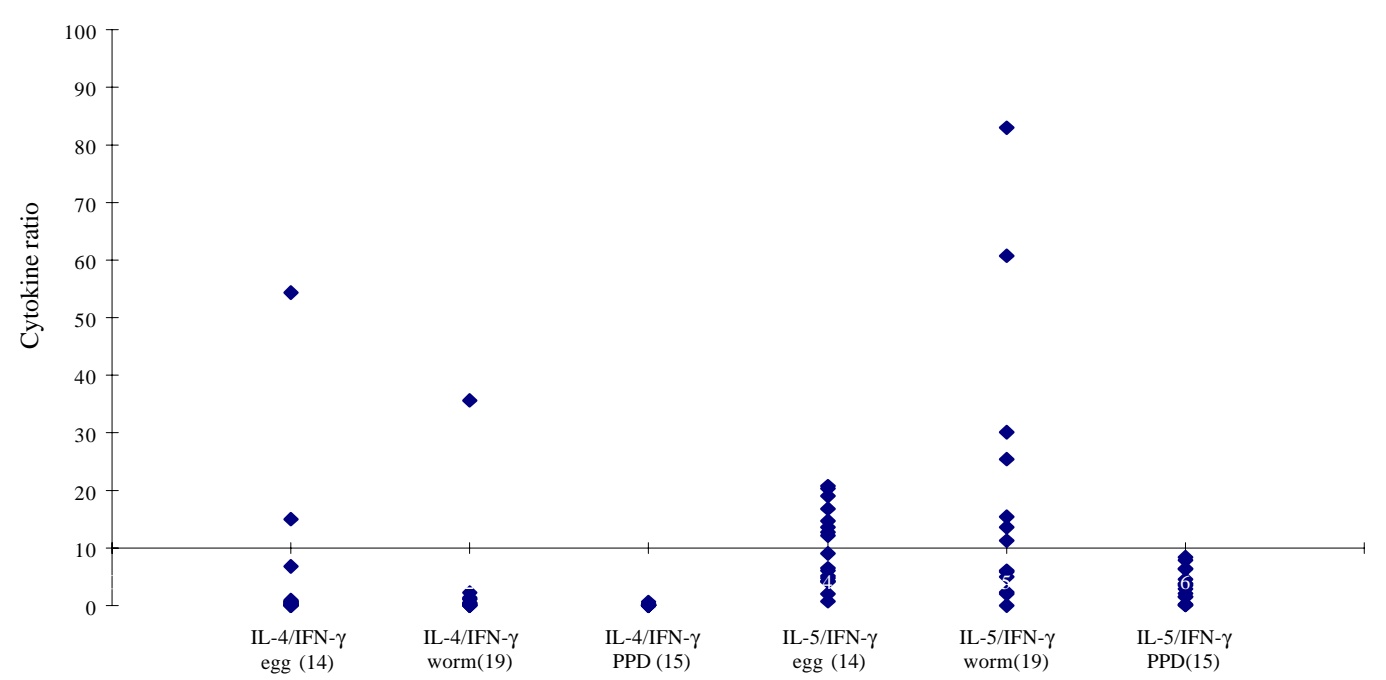

Fig. 2: Schistosoma haematobium infected subject: 309. Cytokine ratios, IL-4:IFN- $\gamma$ and IL-5:IFN- $\gamma$ from the clones according to stimulation with worm (SWAP), egg (SEA) antigen and purified protein derivative (PPD). The number of clones tested is shown in brackets.

showed a low ratio for both comparison of IL-4:IFN$\gamma$ and IL-5:IFN- $\gamma$ (Fig. 3). The infected child, 350, showed an IL-5:IFN- $\gamma$ ratio of approximately 10 , indicating the levels of IL- 5 being 10 times the levels of IFN- $\gamma$ (Fig. 3), indicating the cytokine balance of the response tipping towards a Th2 type. TCC derived from either worm or egg antigen stimulation of PBMC from the moderately infected child, 350 , using IL-4:IFN- $\gamma$ ratio, proved to be predominantly classified as Th0/2 type (Table IIa). A small number of the TCC were classified as Th0/1 and Th2 type. When using the IL-5:IFN- $\gamma$ ratio, a similar distribution of the TCC as for IL-4:IFN- $\gamma$ was observed (Table IIb). The PPD derived TCC produced cytokines that led to their being classified as predominantly $\mathrm{Th} 0 / 2$ with a small number of TCC as Th0/1 and Th1 type (Table IIb).

Child 329 (uninfected) - The mean cytokine ratios from TCC from the uninfected child, 329 showed a high IL-5:IFN- $\gamma$ ratio from the egg antigen derived clones only, with the other ratios being low (Fig. 4). TCC derived from either worm or egg antigen stimulation of PBMC from the uninfected using IL-4:IFN- $\gamma$ ratio, proved to be predominantly classified as Th0/2 type (Table IIa). A small number of TCC were classified as Th0/1 and Th2 type. Using the IL-5:IFN- $\gamma$ ratio, most of the TCC were classified as Th0/2 with a small number of TCC being classified as Th0/1 and Th1 types (Table IIb). The PPD derived TCC produced cytokines that led to their being classified as predominantly Th0/2 with a small number of TCC as Th0/1, Th1 and Th2 type (Table IIb). The cytokines produced led to the TCC being classified as pre- dominantly $\mathrm{Th} 0 / 2$ type, with a small percentage of TCC being classified as Th0/1 and Th1 types). Child 329 , showed a mixed cytokine environment of the response, with neither Th subset dominating

Child 311 (uninfected)- The mean cytokine ratios from TCC from the uninfected child 311 showed higher IL-5:IFN- $\gamma$ ratios than IL-4:IFN- $\gamma$ for all the stimulants (Fig. 5). The TCC from uninfected children showed the IL-5:IFN- $\gamma$ ratio to be higher than the IL-4:IFN- $\gamma$ for the TCC derived from egg and worm antigen stimulation of PBMC. The child 311, showed the IL-4:IFN- $\gamma$ and IL-5:IFN- $\gamma$ ratios being high, showing the levels of IL-4 and IL- 5 to be approximately 10 times the levels of IFN- $\gamma$ (Fig. 5), showing the cytokine environment tipping towards a strong Th0/2 type.

TCC derived from worm and egg antigen stimulation of PBMC from uninfected child, 311, using IL-4:IFN- $\gamma$ ratio, proved to be predominantly classified as Th0/2 type. A small number of T cell clones were classified as Th0/1 and Th2 type (Table IIa). Using the IL-5:IFN- $\gamma$ ratio, similar distribution of the TCC as for IL-4:IFN- $\gamma$ was observed with the TCC predominantly being classified as Th2 type (Table IIb). The PPD derived TCC showed similar classification patterns as for the schistosome antigen derived TCC. The cytokines produced led to the TCC being classified as Th0/2 type, with an increased percentage of TCC being classified as Th2 types.

\section{DISCUSSION}

At the beginning of the study and subsequent follow up after treatment, the children showed dif- 


\section{TABLE IIA}

The distribution of the derived $\mathrm{T}$ cell clones (number) into T helper subsets according to IL-4:IFN- $\gamma$. The T cell clones are classified according to subject and the stimulant used to derive the clones

\begin{tabular}{lrrrr}
\hline Subject/stimulant & Th1 & Th0/1 & Th0/2 & Th2 \\
\hline Infected children & & & & \\
309 worm & & 4 & $\mathbf{1 3}$ & 2 \\
309 egg & 1 & 2 & $\mathbf{1 0}$ & 1 \\
309 PPD & 1 & 7 & $\mathbf{7}$ & \\
350 worm & & 15 & $\mathbf{4 8}$ & 5 \\
350 egg & & 1 & $\mathbf{8}$ & 3 \\
350 PPD & & & $\mathbf{9}$ & \\
Uninfected children & & & & \\
329 worm & 2 & 9 & $\mathbf{3 0}$ & 2 \\
329 egg & & & $\mathbf{1 9}$ & 2 \\
329 PPD & & 3 & $\mathbf{1 0}$ & \\
311 worm & & 1 & $\mathbf{1 2}$ & 4 \\
311 egg & & 4 & $\mathbf{2 7}$ & 5 \\
311 PPD & & 1 & $\mathbf{5}$ & 2 \\
\hline
\end{tabular}

TABLE IIB

The distribution of the derived $\mathrm{T}$ cell clones (number) into $\mathrm{T}$ helper subsets according to IL-5:IFN- $\gamma$ ratio.

The $\mathrm{T}$ cell clones are classified according to subject and the stimulant used to derive the clones

\begin{tabular}{|c|c|c|c|c|}
\hline Subject & Th1 & Th0/1 & $\mathrm{Th} 0 / 2$ & Th2 \\
\hline \multicolumn{5}{|c|}{ Infected children } \\
\hline 309 worm & & & 9 & 10 \\
\hline 309 egg & & 1 & 5 & 9 \\
\hline 309 PPD & & 1 & 14 & \\
\hline 350 worm & & 1 & 32 & 13 \\
\hline 350 egg & & 2 & 9 & 1 \\
\hline 350 PPD & 1 & 4 & 4 & \\
\hline \multicolumn{5}{|c|}{ Uninfected children } \\
\hline 329 worm & 1 & 5 & 32 & \\
\hline 329 egg & 1 & 1 & 10 & 6 \\
\hline 329 PPD & 1 & 4 & 6 & 2 \\
\hline 311 worm & & & 1 & 21 \\
\hline 311 egg & & & 16 & 24 \\
\hline 311 PPD & & & 5 & 3 \\
\hline
\end{tabular}

PPD: purified protein derivative

ferent levels of $S$. haematobium infection, which might be interpreted as supporting the idea from several immunological field studies that individuals living in endemic areas have different immune responses, making them either resistant or susceptible to infection.

$\mathrm{T}$ lymphocytes play a significant and important role in immune responses to infection with schistosomes through the different members of the cytokine classes they produce. During heavy schistosomiasis infection, it is usually observed that the PBMC do not give raised levels of proliferation af- ter stimulation with schistosome-specific antigens. as was reported in adults chronically infected with S. mansoni (Ottesen et al. 1977, 1978, 1979, Colley et al. 1977a, b, 1986, Roberts et al. 1994). The results that the heavily infected child gave very low levels of proliferation to schistosome-specific antigens, while the moderately infected gave slightly raised levels of proliferation were similar to those reported on S. haematobium infected patients (Grogan et al. 1996, King et al. 1996), where unresponsiveness was seen prior to treatment, but increased several fold high after treatment. Such unresponsiveness is thought to be the way the immune response is regulated during heavy infection when the parasite establishes a favourable environment which is beneficial to itself. Since heavy infections normally take some time to accumulate in an individual, the heavily infected child in this study probably acquired their first infections at an early age and might now be considered to have a chronic infection.

Levels of proliferation in non-infected individuals, to the schistosome antigen stimulation were observed to be high thus suggesting an acute infection. During an acute schistosomiasis infection the immune response is characterised by raised levels of proliferation by PBMC on stimulation with schistosome antigen, but during heavy or chronic infection some immune evasion mechanism that includes immunomodulation by the worms renders the host unresponsive to any further stimulation. Some cellular studies (Colley et al. 1977b, Ottesen $\&$ Poindexter 1980, Gazzinelli et al. 1985), reported the presence of some suppressive factors in serum of subjects who had a long duration of infection, which suggested that immunomodulation is a characteristic of those individuals who are heavily or chronically infected, whereas individuals in acute stages of infection have strong cellular responses to specific schistosome antigens. However, in another study (Colley et al. 1986) an association was reported between levels of response to antigens and levels of reinfection. People who were reinfected had lower responses to schistosome antigens than people who remained uninfected. Similar proliferation results were obtained in this study from children 311 and 329, who were uninfected, but child 329 gave lower levels of proliferation to schistosome antigen stimulation than child 311 and became infected earlier.

The TCC from infected children, 309 and 350, and one of the uninfected children, 329 (who became heavily infected early), produced either high levels of IFN- $\gamma$ and IL- 5 but low levels of IL- 4 or similar levels of IFN- $\gamma$ and IL-4. This may indicate that during schistosomiasis infection and susceptibility (as in child 329) either IFN- $\gamma$ is found dominating or the two contrasting cytokines (IFN- $\gamma$ and 


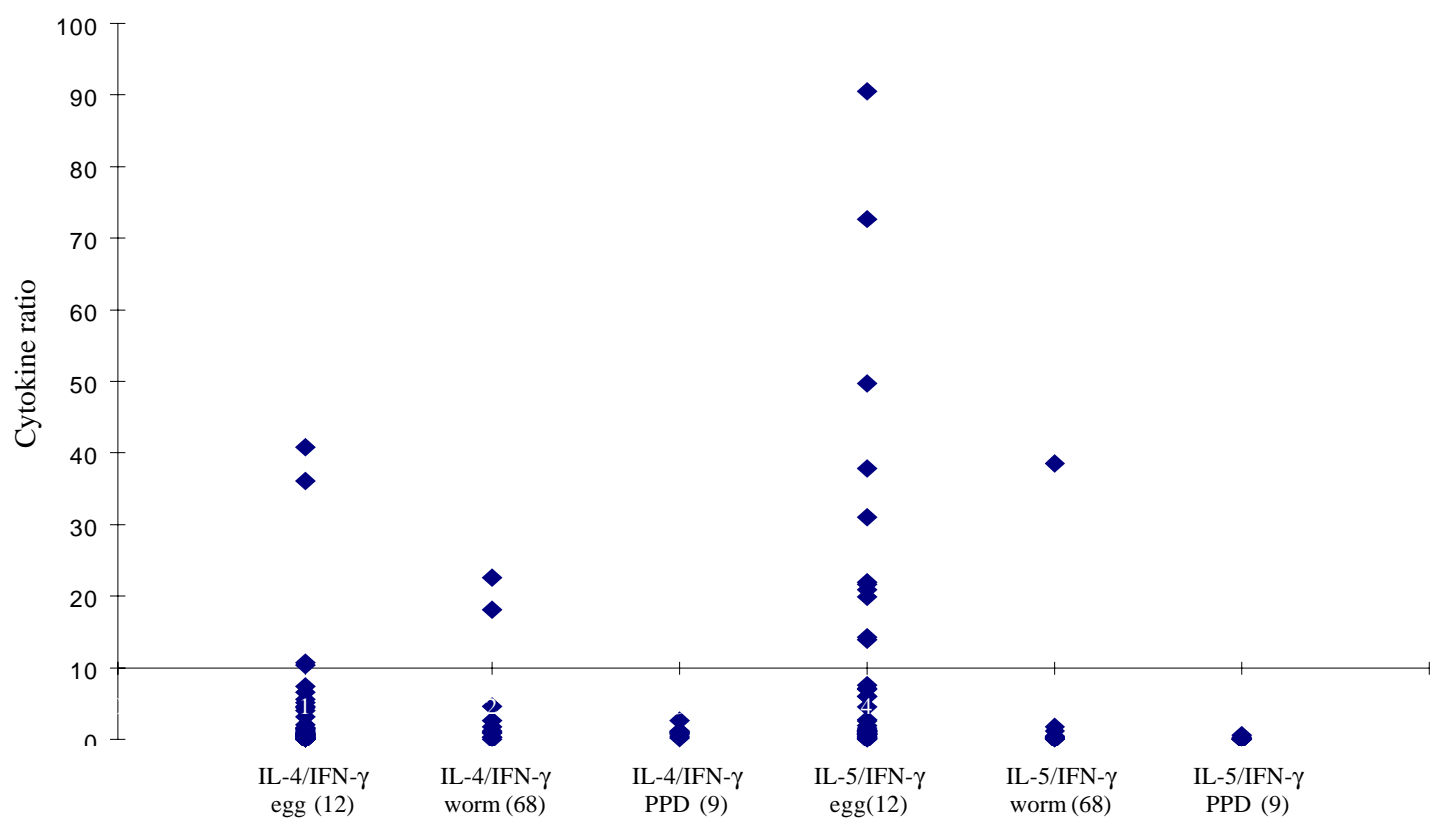

Fig. 3: Schistosoma haematobium infected subject: 350. Cytokine ratios, IL-4:IFN- $\gamma$ and IL-5:IFN- $\gamma$ from the clones according to stimulation with worm (SWAP), egg (SEA) antigen and purified protein derivative (PPD). The number of clones tested is shown in brackets.

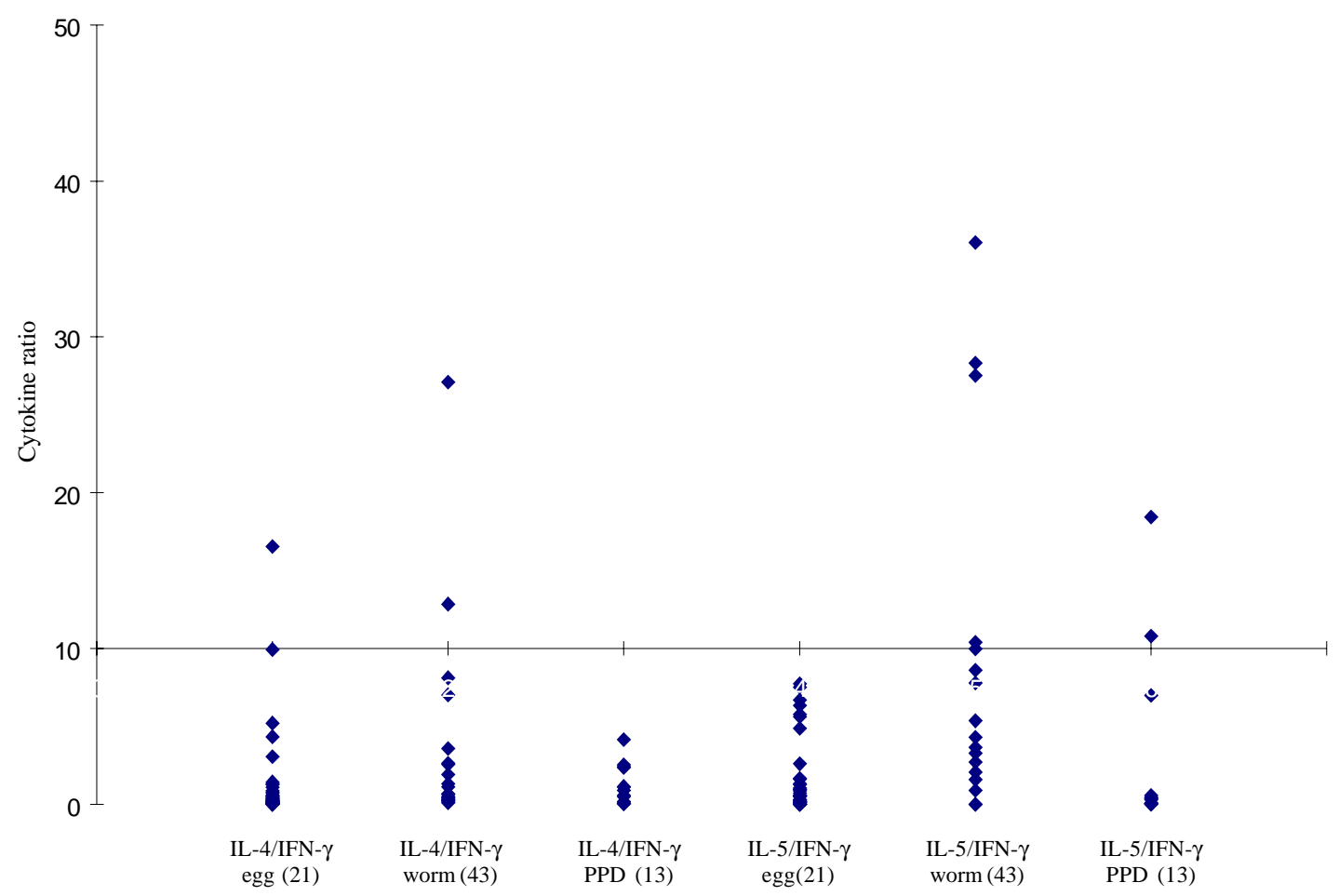

Fig. 4: uninfected subjects: 329. Cytokine ratios, IL-4:IFN- $\gamma$ and IL-5:IFN- $\gamma$ from the clones according to stimulation with worm (SWAP), egg (SEA) antigen and purified protein derivative (PPD). The number of clones tested is shown in brackets. 


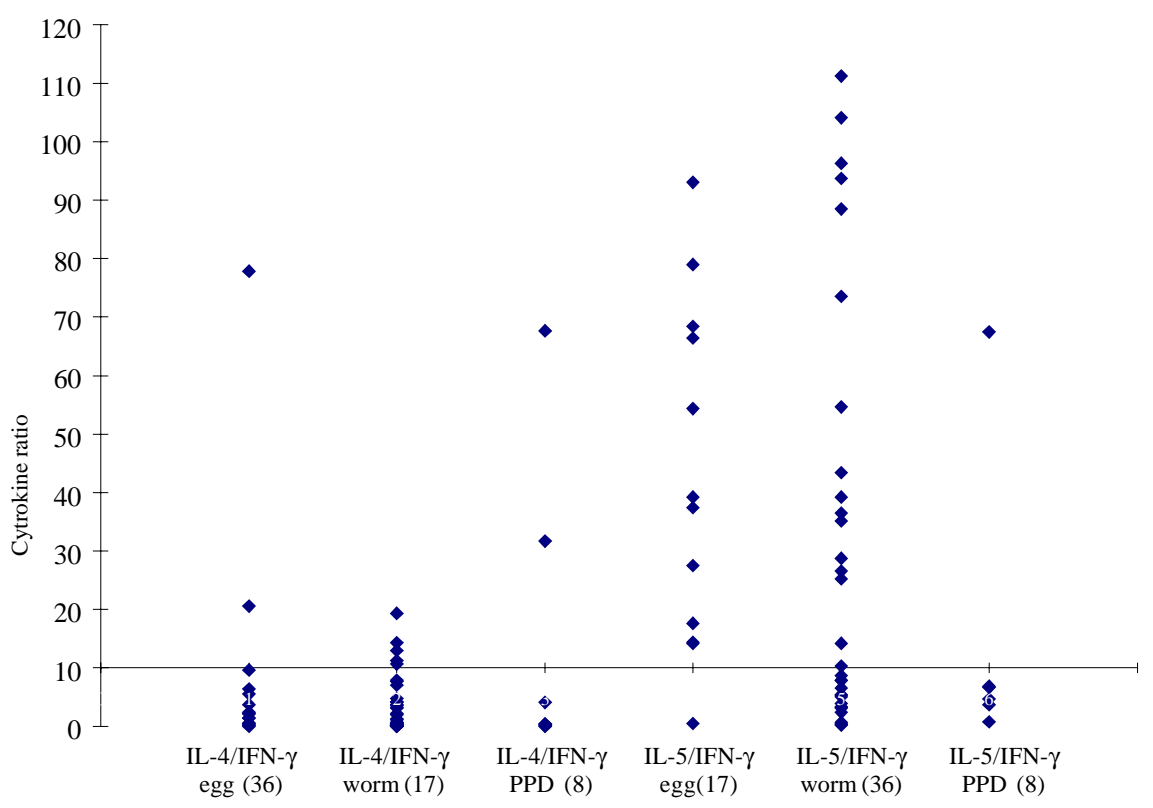

Fig. 5: uninfected subjects: 311. Cytokine ratios, IL-4:IFN- $\gamma$ and IL-5:IFN- $\gamma$ from the clones according to stimulation with worm (SWAP), egg (SEA) antigen and purified protein derivative (PPD). The number of clones tested is shown in brackets.

IL-4) are produced at similar levels, though the sample size limits confidence in this interpretation. The egg antigen derived TCC produced similar levels of IFN- $\gamma$ and IL-4, while the worm antigen derived TCC produced predominantly higher levels of IFN- $\gamma$ than IL-4. This would suggest that differences in responsiveness of the schistosome antigens is dependent on the life cycle stages. The TCC derived by stimulation with egg antigens had the ability to produce IFN- $\gamma$ and IL- 4 at similar levels in individuals who were moderately infected and the child 329 who appeared susceptible to infection. The cytokine levels from the other uninfected child, 311, showed high levels of IL-4 and IL-5, but low levels of IFN- $\gamma$. The fact that high levels of IL4 production may be associated with absence of infection or resistance to infection, may be supported by the results of child number 311 which showed high levels of IL-4 and IL-5. Raised levels of IL-4 and IL-5 (Th2 type cytokines) were clearly related to a lack of infection as shown by high levels in the uninfected child, 311. The TCC from this child were classified as predominantly $\mathrm{Th} 0 / 2$ and Th2, which indicated that a cytokine balance that was dominated by IL- 4 and IL- 5 over IFN- $\gamma$ is protective. The production of IL-4 may suggest a protective role of this cytokine in this child. This supports that IL-4 may be involved in switching B cells to secrete specific antibody isotypes (notably $\operatorname{IgE}$,
IgG1 and IgA) and also that IL-4 may be involved in activation, proliferation, differentiation and enhanced production by B cells of antibodies which may be involved in ADCC reactions during schistosome infection (Romagnani 1991, 1994, Abbas et al. 1996, Mosmann \& Sad 1996).

High IFN- $\gamma$ levels may be a feature of moderately infected individuals or individuals who, though uninfected may be at least partially susceptible to as evidenced by the results of infection. During heavy or chronic infection (as in child 309) much of the T cell responsiveness may be downregulated, effectively 'switched off' and this is reflected in low levels of IFN- $\gamma$. The raised IFN- $\gamma$ levels of the infected child, 350, and uninfected child, 329, may be indicative of continuing $\mathrm{T}$ cell reactivity in these children. The presence of significant levels of IL-4 and IL-5 in these children may indicate that this is a crucial stage in the development of their responses to infection when IL-4 or IL-5 are beginning to dominate the response thus resulting in the dominance of humoral responses. It may be possible to speculate that at this stage the immune responses may continue to develop giving rise to protection. This of course will, in part, be dependent upon the cytokine profile which dominates. The presence of IFN- $\gamma$ may not denote susceptibility but instead a raised level of IFN- $\gamma$ may indicate a developmental stage in acquisition of 
protective immunity with the IFN- $\gamma$ mobilising the cells that may be involved in later protective responses. The presence of IFN- $\gamma$ may mark an immune state which is not sufficient to give complete protection. The dominance of IFN- $\gamma$ may also mark the presence of Th subsets that develop through a Th0 phase then into Th1, during early infection and become further polarised as the infection progresses.

Antigen dosage studies suggest that it is the initial response event that determines the cytokineproducing phenotype and this may be under the influence of factors present at the time of primary stimulation (Parish \& Liew 1972). In these experiments low doses of antigen favoured cellular immunity; intermediate doses, humoral immunity and high doses both cellular and humoral immunity. Assuming that cellular immunity represents IFN- $\gamma$ dominated responses and the humoral immunity, IL-4-dominated responses, commitment to IFN- $\gamma$ or IL-4 production may be determined in part by the concentration of antigen and the time the antigen persists in the body. The data might be used to support the idea that the moderately infected individual (350) and the individual showing the cytokine phenotype tipping towards susceptibility (329) show elevated IFN- $\gamma$ and presence of low levels of IL-4 could be considered to downregulate IFN- $\gamma$ and its likely damaging effects. At the same time IFN- $\gamma$ may be inducing macrophages to express MHC class II for antigen presentation during light infection helping curb the invading parasite and limiting the antigen load by driving the immune response toward killing of the invading parasite. When such an immune response takes place, the events lead to expression of both Th-like responses that resultantly downregulate each other. The cytokine phenotypes lead to the $\mathrm{T}$ cell clones being classified as Th0/2 with some clones being classified as Th0/1 and Th1 for the moderately infected and the susceptible child.

Th1/Th2 polarisation is thought to increase with the chronicity of the immune responses which in turn depends on intensity of exposure to infection and the consequences of the exposure. Some reports have described that mixed cytokine patterns exist early in lymphocyte activation with a clearer Th1 and Th2 subset definition in chronic disease states (Chikunguwo et al. 1991, 1992, Seder et al. 1993, Abbas et al. 1996). Although the children in this study were relatively young and had a limited number of years of exposure to infection (children of one year old are exposed to infection in these communities) chronicity could not be ruled out but, based on the mixed cytokine patterns recorded, any chronicity of infection had not yet been translated into distinct polarisation of $\mathrm{T}$ cell subset responses based on the murine classification. Instead Th0/1 and $\mathrm{Th} 0 / 2$ subsets were isolated and the possibility remains that these could have further differentiated into Th1 and Th2 if exposure and infection had continued.

The children were residents in a S. haematobium endemic area and showed high levels of IL-5. IL-5 is the principal eosinophil-activating cytokine and eosinophils have been reported to be elevated in individuals with parasitic infections (Hagan et al. 1985a, b, Butterworth et al. 1992). However both IL5 and IL- 4 are normally expressed together although at different levels. The co-expression of the two cytokines by the same $\mathrm{T}$ cell subsets may indicate their involvement in a common effector mechanism. Several other cytokines produced by Th2 cells play an anti-inflammatory role. For example, IL-4 and IL10 antagonise the macrophages-activating action of IFN- $\gamma$ (Fiorentino et al. 1991, Del Prete et al. 1993). IL-10 also suppressing macrophage responses resulting in an anti-proliferative response of cells (King et al. 1996). Thus Th2 type cytokine responses may act as inhibitors of acute and chronic inflammation and as a result act as regulators of cellular immune responses and not necessarily as effectors in the same manner as Th1 cells. Th1 may appear early in an immune response, generating a Th1 cell-mediated protective immune response, while Th 2 type comes late to control the damaging effects potentially caused by Th1-mediated response and is believed to accumulate as the response progresses (Pearce et al. 1991, Sher et al. 1991).

Both subsets are believed to originate from the same $\mathrm{T}$ cell precursor whose differentiation is influenced by the manner and environment in which the precursor is stimulated (Swain et al. 1990, 1991, Janeway \& Bottomley 1994). The production of the 'signature' cytokines may indicate the developmental processes to originate from the same precursor cell. During schistosome infection, events may take place in stages with the initial stage being the development of Th1 type of response which has been revealed at a clonal level by the dominance of IFN$\gamma$. The progression of the disease seems to lead into Th2 type response shown by raised levels of IL-4, this status having the ability to suppress the earlier events dominated by IFN- $\gamma$ of the Th1 response. In this study the major 'signature' cytokines marking Th1 or Th2 subsets type were found to be co-expressed by the same $\mathrm{T}$ cell clones. In a study by Couissinier and Dessein (1995) the 'signature' cytokines marking each subset were found to be co-expressed and this resulted in difficulties in classifying the subsets in terms of the Th1 and Th2 subsets reported from murine models. This may mark TCC lacking distinct cytokine pro- 
files for Th1/Th2 polarisation in human schistosomiasis unlike the distinct polarised cytokine profiles marking the Th cell subsets in mice.

In addition to their role in effector immune responses cytokines are also responsible for activating the development of $\mathrm{T}$ cells into particular subset 'lines'. Normally, cytokines produced by a T cell subset serve to activate and increase production of cell lineage which will result in increased frequencies of the same $T$ cell subset and in turn production of the same cytokines (Coffman et al. 1991, Vella \& Pearce 1992, Bradley et al. 1993, Coffman \& von der Weid 1997). When a cytokine reaches a threshold level then that $\mathrm{T}$ cell subset is initiated and the cytokine production increases progressively. With repeated stimulation taking place in individuals in areas of high transmission, the high exposure and continuous stimulation may drive the response in the direction of the first selected response or along the dominating cytokine response. Other factors important in determining the balance between Th1 and Th2 subsets in immune responses are the dose or concentration of the antigen and this may influence the types of responses encountered when infections become chronic. A low antigen concentration and low infection load tends, it seems, to induce Th1 response whereas a high dose induces Th2 development. At low antigen concentration the APC crucial to the response have been reported to be dendritic cells and macrophages which produce the cytokines that drive the development of the Th1 response. At high antigen concentration the APC may not produce the Th1 favouring cytokines, thus IL-4 is produced and further drives the response towards the Th2 type (Seder et al. 1991, 1992, Paul \& Seder 1994, Sprent 1994). Also at high antigen concentration there is repeated $T$ cell stimulation that increases IL-4 production and Th2 development and sometimes induces a state of immunological unresponsiveness or tolerance which switches off Th1 development (Pearce et al. 1991, Swain et al. 1990, 1991). However in this state, as shown by heavily infected child 309 , both subset cytokine markers may be elevated and the levels of proliferation are low.

The study has related the cytokine profiles and phenotypes of TCC from PBMC of children living in a high transmission area of an endemic region. The overall immune response of the individuals in terms of the Th subsets appeared to be related to putative susceptibility or resistance (Fig. 6). The co-expression of 'signature' cytokines by a single human TCC demanded that the standard Th1/Th2 classification from murine studies be modified. As a consequence a revised classification, based on the ratio of cytokines expressed was derived, allowing TCC to be assigned to Th1, Th0/1, Th0/2 and Th2 categories. The $\mathrm{T}$ cell responses appeared to be less stable and more dynamic, suggesting that small quantitative changes in the balance of the cytokines response could result in either susceptibility or resistant to $S$. haematobium infection.

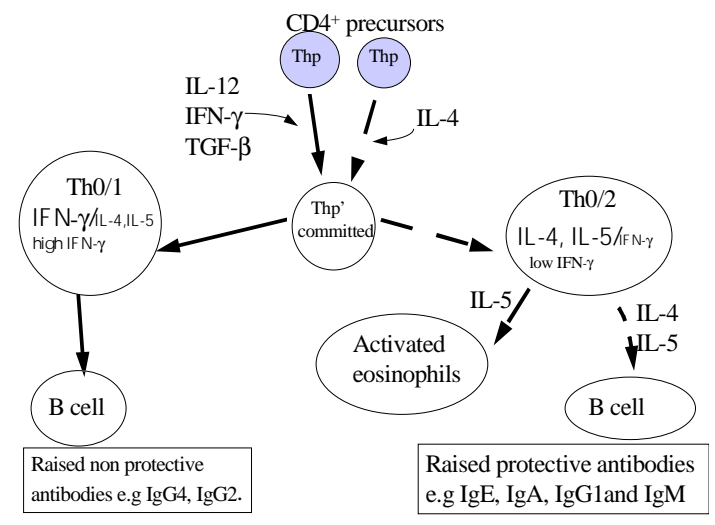

Fig. 6: the cytokine environment in schistosomiasis susceptibility and resistance

\section{ACKNOWLEDGEMENTS}

To the Ministry of Health and Child Welfare of Zimbabwe for the co-operation and permission granted; to the residents of the study area; to the children who participated and the technical assistance provided by the Blair Research Institute staff during the field work.

\section{REFERENCES}

Abbas KA, Murphy MK, Sher A 1996. Functional diversity of helper T lymphocytes. Nature 383: 787793.

Araujo MI, Ribeiro de Jesus AM, Bacellar O, Sabin E, Pearce E, Carvalho EM 1996. Evidence of T helper type 2 activation in human schistosomiasis. Eur $J$ Immunol 26: 1399-1403.

Boyum A 1968. Isolation of mononuclear cells and granulocytes from human blood. Scand J Clin Lab Invest 21: 77-89.

Bradley LM, Duncan DD, Yoshimoto K, Swain SL 1993. Memory effectors: a potent, IL-4-secreting helper T cell population that develops in vivo after restimulation with antigen. J Immunol 150: 31193130 .

Butterworth AE, Dunne DW, Fulford AJC, Thorne KJI, Gachuhi K, Ouma JH, Sturrock RF 1992. Human immunity to Schistosoma mansoni: observation on mechanism, and implications for control. Immunol Invest 21: 391-396.

Chikunguwo SM, Kanazaw T, Dayal Y, Stadecker MJ 1991. The cell-mediated response to schistosomal antigens at the clonal level. In vivo functions of the cloned murine egg antigen-specific $\mathrm{CD} 4^{+} \mathrm{T}$ helper type 1 lymphocytes. J Immunol 147: 3921-3925.

Chikunguwo SM, Harris TS, Brodeur PH, Harn DA, 
Stadecker MJ 1992. The cell-mediated response to schistosomal antigens at the clonal level: development and characterisation of a panel of egg antigenspecific murine $\mathrm{T}$ cell clones. Eur J Immunol 22: 917-922.

Coffman RL, von der Weid T 1997. Multiple pathways for the initiation of $\mathrm{T}$ helper 2 (Th2) responses. $J$ Exp Med 185: 373-375.

Coffman RL, Varikila K, Scott P, Chatelain R 1991. Role of cytokines in the differentiation of $\mathrm{CD}^{+} \mathrm{T}$-cell subsets in vivo. Immunol Rev 123: 189-194.

Colley DG, Barsoum IS, Dahawi MSS, Gamil MF, Habib M, Alamy MA 1986. Immune response and immunoregulation in relation to human schistosomiasis in Egypt. III. Immunity and longitudinal studies of in vitro responsiveness after treatment. Trans $R$ Soc Trop Med Hyg 80: 952-958.

Colley DG, Cook JA, Freeman GL, Bartholomew RK, Jordan P 1977a. Immune responses during human schistosomiasis mansoni. I. In vitro lymphocyte blastogenic response to heterogenous antigenic preparations from schistosome eggs, worms and cercaraie. Intern Arch Allergy Appl Immunol 53: 420-437.

Colley DG, Hieney SE, Bartholomew RK, Cook JA 1977b. Immune response during human schistosomiasis mansoni. III. Regulatory effect of patient sera on human lymphocyte blastogenic responses to schistosome antigen preparations. Am J Trop Med Hyg 26: $917-925$.

Couissinier-Paris P, Dessein AJ 1995. Schistosoma-specific helper $\mathrm{T}$ cell clones from subjects resistant to infection by Schistosoma mansoni are Th0/2. Eur J Immunol 25: 2295-2302.

Del Prete G, De Carli M, Almerigogna F, Giudizi MG, Biagiotti R, Romagnani S 1993. Human IL-10 is produced by both type 1 helper (Th1). and type 2 helper (Th2). T cell clones and inhibits their antigenspecificproliferation and cytokine production. $J$ Immunol 150: 353-360.

Fiorentino DF, Zlotnik A, Mosmann TR, Howard M, O'Garra A 1991. IL-10 acts on the antigen-presenting cell to inhibit cytokine production by Th1 cells. J Immunol 146: 3444-3449.

Gazzinelli G, Lambertucci JR, Katz N, Rocha RS, Lima MS, Colley DG 1985. Immune responses during human schistosomiasis mansoni, XI. Immunological status of patients with acute infections and after treatment. J Immunol 135: 2121-2127.

Grogan JL, Kremsner PG, Deelder AM, Yazdanbakhsh M 1996. Elevated proliferation and interleukin-4 release from $\mathrm{CD}_{4}{ }^{+}$cells after chemotherapy in human Schistosoma haematobium infection. Eur J Immunol 26: 1365-1370.

Hagan P, Moore PJ, Adjukiewics AB, Greenwood BM, Wilkins HA 1985a. In vitro antibody dependent killing of schistosomula of Schistosoma haematobium by human eosinophil. Parasite Immunol 7: 617-624.

Hagan P, Wilkins HA, Blumenthal UJ, Hayes RJ, Greenwood BM 1985b. Eosinophilia and resistance to Schistosoma haematobium in man. Parasite Immunol 7: 625-632.

Hunt VS 1978. Separation of lymphocytes subpopula- tions. In DS Weir, Cellular Immunology. Handbook of Experimental Immunology 3rd ed, Blackwell Scientific Publication, p. 24-39.

Hviid L, Theander TG, Jakobsen PH 1990. Cell-mediated immune responses to soluble Plasmodium falciparum antigens in residents from an area of unstable malaria transmission in The Sudan. APMIS 98: 594-604.

Janeway JCA, Bottomley K 1994. Signals and signs for lymphocyte responses. Cell 76: 275-285.

King CL, Medhat A, Malhotra I, Nafeh M, Helmy A, Khaudary J, Ibrahim S, El- Sherbiny M, Zaky S, Stupi RJ, Brustoski K, Shehata M, Shata MT 1996. Cytokine control of parasite-specific anergy in human urinary schistosomiasis. IL-10 modulates lymphocytes reactivity. J Immunol 156: 4715-4721.

Lefkovits I, Waldmann H 1984. Limiting dilution analysis of the cells of immune system. I. The clonal basis of the immune response. Immunol Today 5: 265268.

Madsen M, Johnson EH, Wendelboe I, Hansen P, Christensen ES 1980. Isolation of human T and B lymphocytes by E-rosette gradient centrifugation. Characterisation of the isolated sub populations. $J$ Immunol Meth 33: 323-328.

Mosmann TR, Cherwisnki HM, Bond MW, Giedlin MA, Coffman RL 1986. Two types of murine helper $\mathrm{T}$ cell clone. I. Definition according to profiles of lymphokine activities and secreted proteins. $J$ Immunol 136: 2348-2357.

Mosmann TR, Coffman RL 1989. Th1 and Th2 cells: different patterns of lymphokine secretion lead to different functional properties. Ann Rev Immunol 7: $145-173$.

Mosmann TR, Sad S 1996. The expanding universe of T-cell subsets: Th1, Th2 and more. Immunol Today 17: 138-146.

Mott KE, Baltes R, Bambagha J, Baldassini B 1982. Field studies of the reusable polyamide filter for detection of Schistosoma haematobium eggs by urine filtration. Propernmedlizin and Parasitologie 33: 227-228.

Ottesen EA, Hiatt JA, Freeman GC, Bartholomew RK, Jordan P 1977. Immune responses during human schistosomiasis mansoni. I. In vitro lymphocyte blastogenesis in response to heterogenous antigenic preparations from schistosome eggs, worms and cercaria. Int Arch Allergy Appl Immunol 53: 420-437.

Ottesen EA 1979. Modulation of the host immune response in human schistosomiasis. I. Adherent suppressor cells that inhibit lymphocyte proliferative response to parasite antigens. J Immunol 123: 16391644.

Ottesen EA, Poindexter RW 1980. Modulation of the host response in human schistosomiasis. ii. Humoral factors which inhibit proliferative responses to parasite antigens. Am J Trop Med Hyg 29: 592-597.

Ottesen EA, Hiatt RA, Cheever AW, Sotomayor RZ, Neva FA 1978. The acquisition and loss of antigenspecific cellular immune responsiveness in acute and chronic schistosomiasis in man. Clin Exp Immunol 33: 38-47. 
Parish CR, Liew FY 1972. Immune response to chemically modified flagellin. III. Enhanced cell-mediated immunity during high and low zone antibody tolerance to flagellin. J Exp Med 135: 298-311.

Paul WE, Seder RA 1994. Lymphocyte responses and cytokines. Cell 76: 241-251.

Pearce EJ, Caspar P, Grzych J, Lewis FA, Sher A 1991. Downregulation of Th1 cytokine production accompanies induction of Th2 responses by a parasitic helminth, Schistosoma mansoni. J Exp Med 173: 159166.

Peters PA, El Alany M, Warren KS, Mahmoud FA 1980. Quick Kato smear for field quantification of Schistosoma mansoni eggs. Am J Trop Med Hyg 29: 217219.

Roberts M, Butterworth AE, Kimani G, Kamau T, Fulford AJC, Dunne DW, Ouma JH, Sturrock RF 1993. Immunity after treatment of human schistosomiasis: association between cellular responses and resistance to reinfection. Infect Immun 61: 4984-4993.

Romagnani S 1991. Human Th1 and Th2 subsets: doubts no more. Immunol Today 12: 256-260.

Romagnani S 1994. Lymphokine production by human $\mathrm{T}$ cells in diseases states. Ann Rev Immunol 12: 227 233.

Seder RA, Gazzinelli G, Sher A, Paul WE 1993. IL-12 acts directly on CD4+ T cells to enhance priming for IFN- $\gamma$ production and diminishes IL-4 inhibition of such priming. Proc Natl Acad Sci USA 90: 1018810192.

Seder RA, Le Gros G, Ben-Sasson SZ, Urban JJ, Finkelman FD, Paul WE 1991. Increased frequency of interleukin 4-producing $\mathrm{T}$ cells as a result of polyclonal priming. Use of single-cell assay to detect interleukin 4-producing cells. Eur J Immunol 21: 1241-1247.

Seder RA, Paul WE, Davis MM, Fazekas de St.Groth B 1992. The presence of interleukin-4 during in vitro priming determines the lymphokine-producing potential of $\mathrm{CD}^{+}{ }^{+} \mathrm{T}$ cells from $\mathrm{T}$ cell receptor transgenic mice. J Exp Med 176: 1091-1098.

Sher A, Coffman RL 1992. Regulation of immunity to parasites by $\mathrm{T}$ cells and $\mathrm{T}$ cell-derived cytokines. Ann Rev Immunol 10: 385-409.

Sher A, Coffman RL, Hieny S, Scott P, Cheever AW 1990. Interleukin 5 is required for the blood and tissue eosinophilia but not granuloma formation induced by infection with Schistosoma mansoni. Proc Natl Acad Sci USA 10: 61-65.

Sher A, Fiorentino D, Caspar P, Pearce EJ, Mosmann TR 1991. Production of IL- 10 by CD4 ${ }^{+}$T lymphocytes correlates with downregulation of Th-1 cytokine synthesis in helminth infection. J Immunol 147: 2713-2716.

Sprent J 1994. T and B memory cells. Cell 76: 315-322.

Swain SL, Bradley LM, Croft M, Tonkonogy S, Atkins G, Weinberg AD, Duncan DD, Hedrick SM, Dutton RW, Huston G 1991. Helper T-cell subsets: phenotype, function and the role of lymphokines in regulating their development. Immunol Rev 123: 115-144.

Swain SL, Weinberg AD, English M, Huston G 1990. IL-4 directs the development of Th2-like helper effectors. J Immunol 145: 3796-3806.

Vella AT, Pearce EJ 1992. CD4+ Th2 response induced by $S$.mansoni eggs develops rapidly through an early transient, Th0-like stage. J Immunol 148: 2283-2290.

Viana IR, Sher A, Carvalho OS, Massara CL, Eloi-Santos SM, Peatce EJ, Colley DG, Gazzinelli G, CorreaOliveira R 1994. Interferon-gamma production by peripheral blood mononuclear cells from residents of an area endemic for Schistosoma mansoni. Trans $R$ Soc Trop Med Hyg 88: 466-470.

Warren KS, Arap Siongok TK, Hanser HB, Ouma JH, Peters PA 1978. Quantitation of infection with Schistosoma haematobium in relation to epidemiology and selective population chemotherapy. 1. Minimal number of daily egg counts in urine necessary to establish intensity of infection. J Infect Dis 138: 849-855.

Williams ME, Montenegro S, Domingues AL, Wynn TA, Teixerira K, Mahanty S, Coutinho A, Sher A 1994. Leukocytes of patients with Schistosoma mansoni respond with a Th2 pattern of cytokine production to mitogen or egg antigens but with a Th0 pattern to worm antigens. J Infect Dis 170: 946-954. 
102 Human T Cell Clones from S. haematobium - T Mduluza et al. 